\title{
EL DESARROLLO DE COMPETENCIAS ORALES Y ESCRITAS EN EL MARCO DEL ESPACIO EUROPEO DE EDUCACIÓN SUPERIOR (EEES). REFLEXIONES, PROPUESTAS Y EXPERIENCIAS EN EL GRADO EN PUBLICIDAD Y RELACIONES PÚBLICAS
}

María Jesús Ruiz-Muñoz¹. Universidad de Málaga. España mariajesus@uma.es

\section{RESUMEN}

Tanto en el ámbito académico como en el terreno profesional, resulta fundamental que las ideas, los trabajos de reflexión crítica y, en general, los proyectos de toda índole estén convenientemente estructurados, redactados y presentados. Asimismo, adquieren gran relevancia en este sentido las habilidades y destrezas comunicativas a la hora de realizar exposiciones en público. Por todo ello, conviene reflexionar acerca del desarrollo de competencias orales y escritas en el actual marco del Espacio Europeo de Educación Superior, especialmente en las titulaciones de Comunicación. En consonancia con lo expuesto, a lo largo del presente trabajo se abordan una serie de consideraciones, propuestas y experiencias relativas a la aplicación de estos planteamientos educativos en el Grado de Publicidad y Relaciones Públicas.

PALABRAS CLAVE: Competencias orales - Competencias escritas - Espacio Europeo de Educación Superior (EEES) - Publicidad - Relaciones Públicas

\footnotetext{
${ }^{1}$ Autor correspondiente

María Jesús Ruiz-Muñoz. Profesora del Departamento de Comunicación Audiovisual y Publicidad de la Universidad de Málaga (España).

Correo: mariajesus@uma.es
} 


\title{
THE DEVELOPMENT OF ORAL AND WRITTEN COMPETENCES IN THE EUROPEAN HIGHER EDUCATION AREA (EHEA). REFLECTIONS, PROPOSALS AND EXPERIENCES IN DEGREE IN ADVERTISING AND PUBLIC RELATIONS
}

\begin{abstract}
Nowadays, for the success of the students and future professionals, it is very important to know how to structure, how to write correctly and how to edit an idea, a critical reflection and, in general, all types of projects. In this framework, it is necessary also to develop communication skills for speaking in public. For this reasons, we have to think about the development of oral and written competences in the European Higher Education Area (EHEA), especially for the Communication studies. This paper presents reflections, proposals and experiences about the application of these educational proposals in Degree in Advertising and Public Relations.
\end{abstract}

KEY WORDS: Oral competences - Written competences - European Higher Education Area (EHEA) - Advertising - Public Relations

\section{INTRODUCCIÓN}

A lo largo del presente trabajo se plantea una reflexión acerca del desarrollo de competencias orales y escritas en el actual marco del Espacio Europeo de Educación Superior en el ámbito de las titulaciones de Comunicación. De manera más específica, se trata de exponer una serie de consideraciones, propuestas y experiencias relativas a la aplicación de estos planteamientos educativos en el Grado en Publicidad y Relaciones Públicas.

Como punto de partida, conviene sistematizar las funciones básicas que desempeña el lenguaje en la formación universitaria. En este sentido, el análisis realizado por Luis Bernardo Peña Borrero resulta sumamente adecuado:

La importancia que tiene el lenguaje en la formación universitaria puede sintetizarse en sus tres funciones principales: una función comunicativa, en cuanto sirve como instrumento para enseñar, evaluar y hacer público el conocimiento; una función social, como mediador en las relaciones interpersonales, los acuerdos y los proyectos cooperativos; y una función epistémica, como herramienta intelectual y de aprendizaje. El énfasis que se la ha dado a la primera de estas funciones ha hecho que se subestime la 
como mediación en los procesos de formación propios de la educación superior (Peña, 2008,)

Por otra parte, en el Libro Blanco para las titulaciones de Comunicación que ha sido editado por la Agencia Nacional para la Evaluación de la Calidad y Acreditación de España, se definen una serie de competencias profesionales, académicas y específicas de diversa índole para el Grado de Publicidad y Relaciones Públicas que se cimentan claramente en la capacidad, habilidad y destreza en el manejo del lenguaje oral y escrito (ANECA, 2005):

a) Competencias profesionales: Capacidad y habilidad para ejercer como profesionales que se encargan de la atención al cliente de la agencia; capacidad y habilidad para responsabilizarse del área de comunicación de un organismo o empresa; capacidad y habilidad para establecer el plan de comunicación; capacidad y habilidad para el ejercicio liberal de la profesión, y la docencia; capacidad relacional y de indagación para establecer una interacción fluida y competente entre el anunciante y la agencia; capacidad y habilidad para dar forma creativa al mensaje; capacidad y habilidad para la creación y desarrollo de elementos gráficos, imágenes, símbolos o textos.; capacidad y habilidad para ejercer como expertos en la gestión estratégica de la imagen corporativa de una empresa; capacidad y habilidad para utilizar las tecnologías y técnicas comunicativas.

b) Competencias académicas: Conocimientos fundamentales de comunicación que sirvan de soporte para su actividad, en función de los requerimientos fijados como conocimientos disciplinares y competencias profesionales; capacidad para asumir el liderazgo en proyectos que requieran recursos humanos y de cualquier otra naturaleza; capacidad para entender e interpretar el entorno y adaptarse al cambio; conocimiento del entorno económico, psicosocial, cultural y demográfico que lo capacite para interactuar con la sociedad; capacidad para la creatividad y la innovación.

c) Otras competencias específicas: Capacidad de relacionarse con las personas y con el entorno sin perder su autonomía; capacidad para trabajar en equipo, desarrollado la apertura personal a través de la comunicación oral y escrita; capacidad de análisis, de síntesis y juicio crítico; capacidad para el análisis objetivo de la realidad y extracción de consideraciones válidas.

En suma, de cara a la adquisición de competencias por parte de los estudiantes de Grado en Publicidad y Relaciones Públicas y a su futuro desarrollo profesional, resulta particularmente importante el aprendizaje y el perfeccionamiento de habilidades comunicativas. En este sentido, además, el docente universitario adscrito a este campo científico no sólo debe ser un adecuado emisor del mensaje educativo sino también transmitir un modelo eficaz en materia de destreza comunicativa. 


\subsection{Construir un discurso, expresarse en público}

Tanto en el ámbito académico como en el terreno profesional, una buena idea, un trabajo de reflexión crítica o un proyecto interesante causarán por lo general más impacto y serán valorados en mayor medida si se organizan y difunden de manera eficaz.

En primer lugar, resulta fundamental la correcta estructuración y elaboración del discurso, prestando especial atención a las características específicas del formato requerido y a la utilización de un lenguaje y un tono adecuados que faciliten la comprensión del contenido. En este sentido, es de gran ayuda la consulta de manuales de redacción y también extrapolar las recomendaciones realizadas para la presentación de proyectos en otras áreas afines.

Por ejemplo, en el caso de la asignatura "Teoría e Historia de las Relaciones Públicas", que se detalla más adelante en el presente trabajo, han resultado especialmente útiles una serie de pautas generales que el entrenador de guionistas y productores Michael Hauge (Hauge, 2006) aconseja para el pitching, es decir, la presentación de proyectos en el mercado audiovisual: Selling your story in 60 seconds. The guaranteed way to get your screenplay or novel read. Michael Wiese Productions. Los Angeles (USA).

Sin duda, una correcta organización del discurso constituye la base fundamental para realizar su exposición en público de manera adecuada. De todos modos, en lo que respecta al desarrollo y perfeccionamiento de habilidades comunicativas, no sólo es necesario trabajar la comunicación escrita, la verbal y la no verbal, sino que también conviene reforzar el aprendizaje con la enseñanza de la aplicación de técnicas de expresión gráfica y audiovisual a la presentación de proyectos.

\subsection{Comunicación verbal y comunicación no verbal}

A lo largo de los años, muchos han considerado que la elocuencia o capacidad para hablar en público es una cualidad innata que unos tienen la suerte de poseer y otros no. Aunque también están quienes han defendido que las habilidades comunicativas sólo pueden adquirirse a través del aprendizaje. En la actualidad, como señala Ezequiel Ander-Egg, "existe un acuerdo bastante generalizado que establece que la capacidad para hablar en público es una combinación de lo innato y lo adquirido; es un don y es una conquista" (Ander-Egg, 2006, p. 25).

Por tanto, a la hora de trabajar la expresión oral en el aula, además de proporcionar unas pautas generales al grupo, es recomendable conocer las cualidades previas de los diferentes alumnos para personalizar en la medida de lo posible el proceso de enseñanza-aprendizaje en función de las características específicas de cada uno de -11- 
En la práctica docente aquí descrita se ha advertido, entre otros aspectos, que los alumnos con experiencia en artes escénicas y en el medio radiofónico poseían a priori mayores habilidades en el manejo de la voz y no presentaban dificultades a la hora de enfrentarse a obstáculos psicológicos como la timidez cuando se trataba de hablar en público. La distribución estratégica de estos alumnos en diferentes grupos de trabajo ha resultado eficaz para contribuir a mejorar las carencias que presentaban algunos sus compañeros en este sentido

En lo que respecta a la comunicación verbal, resulta esencial conocer las características de la voz (registro, timbre, tono, volumen, inflexiones) y de las principales variables que determinan su correcta utilización en una exposición oral (respiración, entonación, vocalización, ritmo). No obstante, la adecuada aplicación en la práctica de estos conocimientos queda condicionada en buena medida por la persistencia de cada alumno en el ensayo de ejercicios concebidos para tal fin (Tirado Ruiz, Ruiz del Árbol \& Albar, 2003), (Huertas Bailén, \& Perona Páez, 1999).

Por otro lado, para transmitir un mensaje de manera eficaz, resulta fundamental cuidar la expresión corporal, que debe ser coherente con lo que se está diciendo con palabras. Así pues, conviene cuidar los gestos y los movimientos, teniendo presente que el cuerpo también constituyen una fuente de información para los oyentes.

La reacción del auditorio puede servir al expositor como un poderoso aliado que le indica si está transmitiendo bien o no el mensaje que pretende trasladar a través de su discurso. Por ello, numerosos autores, como Marina Cuervo y Jesús Diéguez, insisten en la importancia de ensayar con público y recomiendan la realización de ejercicios en este sentido:

La postura y los gestos de brazos y manos son algo muy personal y dependen también del público que nos escucha: ante una gran asamblea los gestos deberán ser más lentos y amplios que ante un grupo reducido de personas. Con la ayuda y orientaciones de los componentes del grupo ensayaremos sobre la tarima algunos, pocos, movimientos y gestos evitando por una parte la teatralidad y por otra el encogimiento. (Cuervo \& Diéguez, 2001, p. 153)

En última instancia, las técnicas de expresión oral deben convivir en armonía con la utilización de recursos gráficos y audiovisuales en todo tipo de presentaciones ante un auditorio. 


\subsection{Complementariedad de técnicas de expresión escrita, oral, gráfica y audiovisual}

En el contexto educativo actual, el perfil del alumno universitario, usuario de los medios de comunicación, es cada vez más interactivo. Este potencial para el aprendizaje debe ser aprovechado por el profesorado, haciendo hincapié más que nunca contra la sobreabundancia de información y a favor de una organización clara de los contenidos que permita facilitar la comprensión.

Los jóvenes sienten una fascinación por las nuevas tecnologías y tienen una enorme facilidad para desenvolverse con ellas. Han integrado además entornos virtuales como la mensajería instantánea en su forma de relacionarse con los demás, hasta el punto de no establecer una barrera clara entre los contactos a través de la red y los contactos presenciales. Tienen una preferencia clara por las imágenes frente al texto, una habilidad innata para la orientación espaciovisual fruto de su experiencia con juegos digitales, una clara tendencia hacia el aprendizaje a través de la exploración y una sorprendente capacidad para mantener la atención sobre varios focos de forma simultánea (Ovelar \& Romo, 2009, p. 41)

Con el paso del tiempo, el vídeo tradicional ha ido dejando paso al ordenador. Y allí, la blogosfera y los sitios web como Youtube y Megavideo constituyen una fuente inagotable de material audiovisual. Así pues, debemos poner especial énfasis a la hora de enseñar a los alumnos a seleccionar los recursos gráficos y audiovisuales adecuados para sus exposiciones, con el fin de que aprendan que éstos deben servir para ilustrar y dinamizar el discurso, no para saturar a sus destinatarios, y que no deben interferir negativamente como un bombardeo indiscriminado de estímulos que entorpezca la comprensión del mensaje.

Entre las llamadas de atención sobre de los abusos de las herramientas tecnológicas y de los estímulos audiovisuales en la enseñanza, encontramos una constructiva reflexión de Ramón Cladellas en torno a la utilización de presentaciones gráficas que resulta bastante concluyente en el sentido descrito: 
Dichas proyecciones presentan la misma información que podría facilitarse mediante fotocopias o el uso de la pizarra (o en un fichero informático) la cual acaba siendo copiada -ja mano!- por el alumnado. Como medio de acceso a la información es altamente perverso ya que acaba combinando un recurso tecnológico potente con un mecanismo medieval (la copia manuscrita). En muchas aulas, las pantallas de proyección se solapan físicamente con la pizarra, en lo que es una substitución implícita. Pero, si los materiales proyectados podrían también presentarse en la antigua pizarra, las ganancias de la nueva tecnología parecen banales (menos tiza en las manos y, quizá, una tipografía más clara). Algo muy distinto es que se utilice esta tecnología para presentar información icónica (esquemas, imágenes, diagramas, planos, vídeos) más difíciles de plasmar en la pizarra o imposibles de presentar con dicho medio. (Cladellas, 2010)

Así pues, si los profesores sobrecargamos las presentaciones, las utilizamos como un teleprompter y olvidamos el sentido unitario que deben tener el texto y la imagen, estaremos dando un mal ejemplo a los alumnos. Además, éstos correrán un grave riesgo de "muerte por PowerPoint" (Suárez, 2010). Semejantes patologías podrían diagnosticarse igualmente en casos de abuso de vídeos o páginas web: "muerte por Media Player" y "muerte por Flash", respectivamente. Y, en circunstancias extremas, también podría darse una suma de todos estos factores.

Por todo ello, el profesor universitario debe utilizar los recursos audiovisuales en aras del proceso de aprendizaje, no para rellenar tiempos muertos ni para mecanizar su tarea. Y el alumno debe aplicar esta misma recomendación tanto a las exposiciones que realice en el aula como a las presentaciones en público que lleve a cabo en un futuro en el ejercicio de su profesión.

Finalmente, como señala Luis Puchol (Puchol 2008, p. 205), cabe subrayar que cuando no se utilizan bien los medios audiovisuales:

a) Pueden distraer a la audiencia del mensaje al atraer sobre sí mismos la atención que el expositor desea que los asistentes dediquen a su exposición.

b) Pueden distraer también al propio expositor, ya que tiene que diversificar su atención a hablar mientras manipula los aparatos.

c) Pueden confundir a la audiencia si lo que se muestra en las imágenes no coincide con lo que el expositor está expresando verbalmente.

\subsection{Experiencia de trabajo basado en competencias orales y escritas en el Grado en Publicidad y Relaciones Públicas}

A continuación, se analiza la experiencia de enseñanza-aprendizaje de técnicas de expresión oral v escrita llevada a cabo en el marco de la asignatura "Teoría e Historia 
los cinco grupos prácticos de la mencionada asignatura a lo largo del primer semestre del curso académico 2010-2011.

\subsection{Objetivos}

Los principales objetivos de esta línea de innovación, escasamente explorada hasta el momento a pesar de su relevancia, han sido los siguientes:

a) Proporcionar herramientas que permitan a los alumnos mejorar su expresión escrita y oral de cara a la presentación de proyectos en el ámbito académico y profesional.

b) Potenciar el desarrollo de habilidades sociales y comunicativas que resulten útiles en el ejercicio de la profesión de Relaciones Públicas.

c) Especialmente al tratarse de alumnos de primer curso, contribuir a afianzar sus recursos y a descubrir otros nuevos que les permitan ejecutar de manera creativa, planificada y segura las presentaciones académicas que deben realizar en el marco de ésta y otras asignaturas.

\section{METODOLOGÍA}

Para el cumplimiento de los objetivos descritos, a través del diseño metodológico, se ha puesto énfasis en incentivar el trabajo cooperativo, reforzar el aprendizaje mediante actividades de acción tutorial y desarrollar técnicas de autoevaluación para los alumnos y de seguimiento y evaluación de su proceso de aprendizaje por parte de la profesora responsable de la parte práctica de la materia.

Al comienzo del semestre, se realizaron en el aula dos sesiones explicativas sobre técnicas de elaboración del discurso, presentación de proyectos, utilización de las TICs y recursos de expresión oral. Asimismo, se facilitaron a los alumnos referencias bibliográficas complementarias de interés.

Durante el transcurso de la asignatura, los alumnos han realizado en equipos de cinco personas cuatro trabajos prácticos relacionados con diferentes ámbitos de las Relaciones Públicas que posteriormente han defendido ante sus compañeros y la profesora.

Tras cada exposición, los alumnos han recibido observaciones por parte de sus compañeros, han realizado ejercicios de autoevaluación y han acudido a tutoría para reflexionar acerca de la exposición con la profesora. 
También cabe destacar que, de manera voluntaria, un nutrido conjunto de alumnos ha acudido a tutoría en los días previos a su exposición para plantear dudas, dificultades e incluso inseguridades con el fin de avanzar en el proceso de aprendizaje.

\section{ANÁLISIS Y DISCUSIÓN}

La experiencia llevada a cabo ha resultado sumamente positiva tanto por los resultados obtenidos de la evaluación continua de los trabajos realizados como por la valoración realizada por los alumnos, que ha quedado reflejada en una encuesta final sobre la parte práctica de la asignatura.

En primer lugar, cabe subrayar que la evaluación continua ha permitido detectar problemas e ir dosificando soluciones a éstos a lo largo del curso, de manera que en general los alumnos han ido avanzando progresivamente entre la realización de una práctica y la siguiente, como también ha quedado reflejado en sus calificaciones.

Por otro lado, al término de las clases, se les ha proporcionado a los alumnos una encuesta de carácter voluntario acerca de la parte práctica de la asignatura, que ha alcanzado el $90 \%$ de participación, en la que se ha puesto especial énfasis, entre otras, en las siguientes cuestiones relacionadas con la incorporación de técnicas de expresión oral:

a) ¿Te han resultado útiles las siguientes técnicas para la exposición de trabajos: sobre estructura y organización del discurso, sobre diseño y utilización de presentaciones gráficas, sobre selección y utilización del material audiovisual, sobre expresión oral, sobre expresión corporal?

b) ¿Crees que las técnicas para la exposición de trabajos que se han explicado en clase te han resultado útiles para esta asignatura? ¿Te resultarán útiles para otras asignaturas? ¿Y para aplicarlas en tu futura profesión?

c) En general, ¿has aprendido a planificar y realizar mejor las exposiciones: por el trabajo que has realizado con tu equipo, porque te ha servido atender durante las presentaciones de otros equipos, por las indicaciones de la profesora en clase, por la consulta de bibliografía de interés?

d) Las técnicas para la exposición de trabajos que se han explicado en clase sirven para vender mejor un trabajo o un proyecto.

e) Son útiles para dar una buena imagen en público.

f) Son de gran ayuda para condensar y transmitir lo esencial de un proyecto.

En la primera de las cuestiones, los alumnos han destacado, con calificaciones que oscilan mayoritariamente entre bastante y mucho, las técnicas sobre expresión oral, sobre expresión corporal, $\mathrm{v}$ sobre utilización de presentaciones gráficas $\mathrm{v}$ material 
Respecto a la utilidad de las técnicas para la exposición de proyectos, el 100\% de los alumnos encuestados han respondido afirmativamente para el caso de otras asignaturas y para aplicarlas en su futuro desarrollo profesional. Acerca de la asignatura de Relaciones Públicas en cuestión, solamente una persona ha respondido que no le ha resultado útil.

En lo que se refiere al grado de aprendizaje, las valoraciones han sido positivas en todas las encuestas. No obstante, cabe matizar que los aspectos destacados por los alumnos en esta línea han sido la atención durante las presentaciones de los otros equipos, el trabajo realizado con el propio equipo y las indicaciones de la profesora en clase. Mientras que estos puntos han obtenido una calificación entre mucho y bastante, la consulta de bibliografía se ha revelado como poco o nada útil.

En general, los alumnos han percibido en gran medida la utilidad de las técnicas de exposición para organizar y difundir ideas y proyectos, tanto en el ámbito educativo como en el profesional.

\section{CONCLUSIONES}

Como ya se ha puesto de relevancia anteriormente, la experiencia de introducir técnicas para trabajar las competencias comunicativas en el proceso de enseñanzaaprendizaje de la asignatura "Teoría e Historia de las Relaciones Públicas" del Grado en Publicidad y Relaciones Públicas ha sido altamente fructífera. En este sentido, la receptividad y el interés por parte de los alumnos en lo que respecta a la incorporación de las herramientas de innovación descritas ha resultado un elemento clave para desarrollar una metodología basada en buena parte en la evaluación continua.

Por otro lado, queda patente la carencia de publicaciones en las que se dé cuenta de experiencias similares en el marco del EEES, tanto en el contexto del campo científico que nos ocupa como en otros más o menos próximos. Así pues, conviene apostar por el desarrollo de iniciativas de investigación e innovación acerca del uso de técnicas de expresión oral y escrita en el aula, concebidas igualmente par su aprovechamiento en el ámbito profesional, y también demetodologías de elaboración de materiales didácticos al respecto.

Además de potenciar el análisis de estos planteamientos desde la investigación e innovación educativa, es necesario fomentar el intercambio de experiencias docentes en la misma línea. En este sentido, se revela como particularmente enriquecedor poder contar con un mayor número de iniciativas en el ámbito del Grado en Publicidad y Relaciones Públicas y del resto de titulaciones de Comunicación. 
En general, apostamos por incentivar la incorporación de técnicas de expresión oral y de utilización de recursos escritos, gráficos y audiovisuales en los programas de formación continua para alumnos y profesores universitarios que, cada vez más, forman parte de la oferta de los propios centros educativos.

\section{REFERENCIAS}

Alcoba, S. (2000). La expresión oral. Barcelona: Ariel.

Ander-Egg, E. (2006). Hablar en público y saber comunicar. Buenos Aires: Lumen.

ANECA (2005). Libro Blanco. Títulos de grado en Comunicación. Recuperado el 08 de noviembre de 2011, de

http://www.aneca.es/var/media/150336/libroblanco_comunicacion_def.pdf

Cladellas, R. (2010). Aportes y perjuicios de las TIC's a la Educación En Actas del Congreso Internacional Europa/América Latina ATEI. Alfabetización mediática y culturas digitales. Sevilla: Universidad de Sevilla.

Cuervo, M. \& DIÉGUEZ, J. (2001). Mejorar la expresión oral. Animación a través de dinámicas grupales. Madrid: Narcea.

García Serrano, F. (2009). Las técnicas del pitching en el mercado audiovisual español: del caramelo al guión En Actas del I Congreso Internacional Brand Trends. Valencia: CEU Universidad Cardenal Herrera.

González Ramírez, J. F. (1998). Lenguaje corporal: claves de la comunicación no verbal. Madrid: Edimat.

Hauge, M. (2006). Selling your story in 60 seconds. The guaranteed way to get your screenplay or novel read. Los Angeles: Michael Wiese Productions.

Huertas Bailén, A. \& Perona Páez, J. J. (1999). Redacción y locución en medios audiovisuales: la radio. Barcelona: Bosch.

Lorente, E.; Doblas, P. \& Zaldumbide, I. (2010). El desarrollo de competencias en comunicación. El proyecto como metodología de enseñanza-aprendizaje En Actas del II Congreso Internacional Latina de Comunicación Social. Universidad de La Laguna. Tenerife. Recuperado el 08 de diciembre de 2011, de http://www.revistalatinacs.org/10SLCS/actas_2010/40Lorente2.pdf

Merayo, A. (2001). Curso práctico de técnicas de comunicación oral. Madrid: Tecnos. 
Ovelar, R.; Benito, M. \& Romo, J. (2009). Nativos digitales y aprendizaje. Icono. 14(12). Recuperado el 08 de diciembre de 2011, de http:/ / www.icono14.net .

Peña Borrero, L. B. (2008). La competencia oral y escrita en la educación superior. Recuperado el 08 de diciembre de 2011, de http://www.mineducacion.gov.co/1621/articles189357 archivo_pdf_comunicacion.pdf

Puchol, L. (2008). Hablar en público. Nuevas técnicas y recursos para influir a una audiencia en cualquier circunstancia. Madrid: Díaz de Santos.

Rosales López, C. (1987). Didáctica de la comunicación verbal. Madrid: Narcea.

Ruiz Muñoz, M. J. (2010). La utilización didáctica de recursos audiovisuales en el escenario de la convergencia mediática En Métodos de innovación docente aplicados a los estudios de Ciencias de la Comunicación. Madrid: Fragua.

Suárez, C. (2010). Cómo evitar la muerte por PowerPoint En Educación y virtualidad. Avances interdisciplinarios en materia educativa y virtual. [En línea] Recuperado el 08 de diciembre de 2011, de http://educacion-virtualidad.blogspot.com).

Tirado Ruiz, J. A.; Ruiz del Árbol, M. \& ALBAR, M. I. (2003). Técnicas para leer y escribir en radio y televisión. Barcelona: Bosch.

Yera Jacomino, D. (2011). Las habilidades comunicativas en estudiantes de la especialidad Contabilidad y Finanzas: una propuesta de actuación. Cuadernos de Educación y Desarrollo, 3(28). Recuperado el 08 de diciembre de 2011, de http://www.eumed.net.

\section{María Jesús Ruiz-Muñoz}

Doctora en Comunicación Audiovisual y Publicidad por la Universidad de Málaga. Máster en Guión de Televisión por la Universidad Internacional Menéndez Pelayo Fundación para la Investigación del Audiovisual (Valencia) y Máster Internacional de Escritura para Cine y Televisión, especialidad de Análisis, por la Universitat Autònoma de Barcelona. Licenciada en Publicidad y Relaciones Públicas y Licenciada en Periodismo por la Universidad de Málaga. Profesora del Departamento de Comunicación Audiovisual y Publicidad de la Universidad de Málaga. Su línea de investigación gira en torno al estudio de la representación de identidades culturales en los medios audiovisuales. Sus trabajos en torno a éste y otros temas relacionados con la Narrativa audiovisual han sido difundidos en congresos y revistas nacionales e internacionales. Ha realizado diversas estancias de investigación en la Universidad Nacional de Córdoba (Argentina) y ha cursado estudios en otros centros internacionales de prestigio como la Escuela Internacional de Cine de San Antonio de 1 .. n . . . in . 1. . I 